
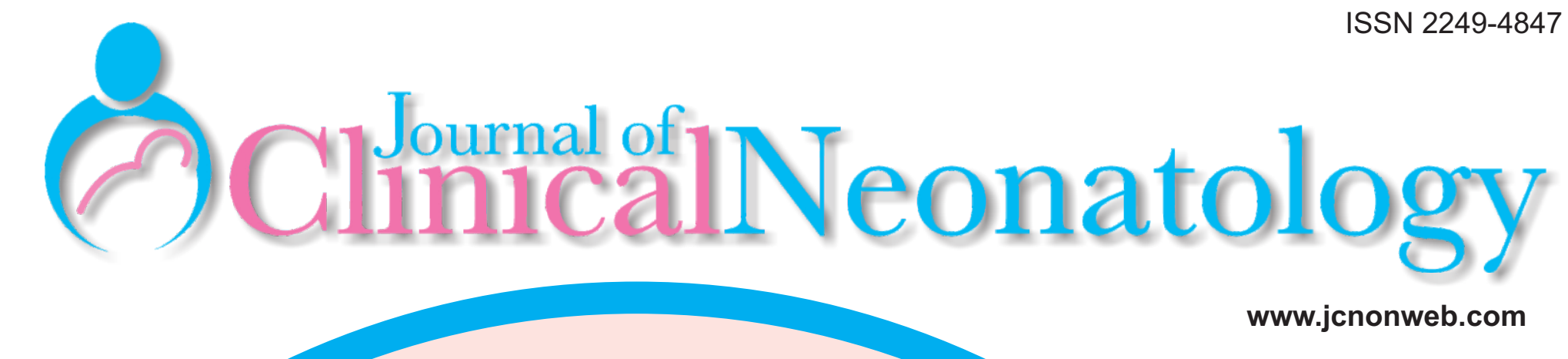

Original Articles

Prevalence and Outcome of Pulmonary Arterial Hypertension in Newborns with Perinatal Asphyxia Tauqueer Ahmed, Shaad Abqari, Tabassum Shahab, Syed Manazir Ali, Uzma Firdaus, Iraj Alam Khan 63 Impact of the NeoResus Training on Nonpediatric-Trained Medical and Nursing Staff in the Emergency Department: Experience from Two Sites in Regional Australia Anutosh Shee, Mandy Gleeson $\quad 67$

Insulin Resistance Profile of Apparently Healthy Term Neonates in Lagos, Nigeria Ibironke J. Akinola, Elizabeth E. Oyenusi, Olatunde A. Odusote, Abiola O. Oduwole, Fidelis O. Njokanma 71 Late and Moderately Preterm Babies in a Tertiary Childrens' Hospital in India: Its Time we Took a Closer Look Rajasri Rao Seethamraju, Neelima Kharidehal, Vamsi Kiran Rayudu 75

A 4-Year Prospective Study of Clinico-bacterial Profile and Antibiogram of Neonatal Bacterial Sepsis at a Tertiary Health Facility in a Resource-limited Setting

Uchenna Ekwochi, Christian Ifediora, Chidiebere D. I. Osuorah 80

Retention of Knowledge and Skill of Birth Attendants in Newborn Care and Resuscitation after 1 Year in Clinical Practice: An Experience from India

Manoja Kumar Das, Chetna Chaudhary, Surender Singh Bisht, Arti Maria, Ashish Jain, Santosh Kumar Kaushal, Rajesh Khanna, Surojit Chatterji 89

Case Reports

Hypocalcemia, Seizures, and Impairment of Vision in a Neonate

Sashi Kumar Kona, Naga Jaya Smitha Yenduri, Nidhi Agarwal, Raghu Ramakrishnaiah, Weston Miller 96

Congenital Sublingual Cyst Masking the Airway: Ex Utero Intrapartum Treatment to Life!

Iyer Harohalli Venkatesh 99

Congenital Hernia of the Umbilical Cord with Patent Vitello-intestinal Duct in a Newborn: A Rare Case

Aditya Pratap Singh, Arun Kumar Gupta, Ramesh Tanger, Dileep Garg 102

Sternocleidomastoid Pseudotumor: APrompt Fine-Needle Aspiration Cytology Diagnosis

Rohi Wani, Manzoor Ahmad, Salma Bhat, Sheema Sheikh 105

Management of an Infant with Congenital Factor VII Deficiency Presenting with Obstructed Inguinal Hernia

Minakshi Bhosale, Sonali Salvi, Rajesh Kulkarni, Savita Rangarajan 108 


\title{
A 4-Year Prospective Study of Clinico-bacterial Profile and Antibiogram of Neonatal Bacterial Sepsis at a Tertiary Health Facility in a Resource-limited Setting
}

\author{
Uchenna Ekwochi, Christian Ifediora ${ }^{1}$, Chidiebere D. I. Osuorah ${ }^{2}$
}

Department of Paediatrics, Enugu State University of Science and Technology, Enugu, Nigeria, ${ }^{1}$ Griffiths University Medical School, Gold Coast, Australia, ${ }^{2}$ Child Survival Unit, Medical Research Council UK, Gambia Unit, Fajara, The Gambia
Background: In the developing countries, neonatal sepsis (NNS) contributes significantly to neonatal admissions and deaths. Its symptoms are usually nonspecific, and definitive laboratory diagnosis can be challenging in a resource-limited setting. Therefore, early empirical antibiotic therapy antibiotics are important in these localities, and this makes it important to document local organisms and their antibiotic sensitivity pattern. Unfortunately, no previous study in our setting has documented these. Methods: This study involved newborns (inborn and outborn) admitted with sepsis (cases) within the $1^{\text {st }}$ month of life at the Enugu State University Teaching Hospital (ESUTH), Enugu, Southeast Nigeria. Controls were included for the analysis, and data were collected over a 4-year period from January 2013 to December 2016. Results: In all, 1920 newborns were admitted to the Special Care Baby Unit of ESUTH during the study period. Fifty-seven were managed for culture-proven sepsis, resulting in an in-hospital incidence rate of 29.7 per 1000 admitted newborns (95\% confidence interval 21.9-37.4). A total 228 newborns were recruited (57 cases and 171 controls; ratio of 1:3). The most common presenting symptom and sign were fever $(84.2 \%)$ and depressed primitive reflexes $(50.9 \%)$, respectively. A case-fatality rate of $7.4 \%$ was observed. Newborn's place of birth $(P=0.02)$ and the final outcome $(P=0.004)$ were significantly associated with the development of sepsis, while gender $(P=0.12)$, birth weight $(P=0.33)$, gestational age $(P=0.53)$, and mode of delivery $(P=0.74)$ were not. Nearly $60 \%$ of the organisms implicated were coliforms, while one-quarter were Staphylococcus aureus. The most sensitive antibiotics were the fluoroquinolones, particularly ciprofloxacin, while amoxicillin, ampicillin, and clindamycin were generally not effective. Conclusion: NNS in our environment is commonly caused by coliforms and $S$. aureus and being outborn is a significant determinant. Antibiotic resistance follows recognized patterns, but the quinolones, despite their inconclusive safety profile in children, are most sensitive.

KEYWORID: Antibiogram, clinical features, Enugu, neonates, sepsis

\section{INTRODUCTION}

Cepsis is a systemic inflammatory response $\int$ syndrome due to infection. ${ }^{[1]}$ Neonatal bacterial sepsis specifically refers to sepsis caused by bacteria in the first 28 days of life. Systemic inflammatory syndrome includes two or more of the following clinical features: fever, hypothermia, tachycardia, tachypnea, and abnormal white blood cells in immature

\begin{tabular}{|l|l|}
\hline \multicolumn{2}{c|}{ Access this article online } \\
\hline Quick Response Code: & \\
& \\
\hline
\end{tabular}

forms. ${ }^{[1]}$ Globally, neonatal deaths are caused by infections (which include sepsis/pneumonia, tetanus, and diarrhea) which account for $36 \%$, preterm $28 \%$, and

Address for correspondence: Dr. Chidiebere D. I. Osuorah, Child Survival Unit, Medical Research Council UK, Gambia Unit, Fajara, The Gambia. E-mail: chidi.osuorah@gmail.com

This is an open access article distributed under the terms of the Creative Commons Attribution-NonCommercial-ShareAlike 3.0 License, which allows others to remix, tweak, and build upon the work non-commercially, as long as the author is credited and the new creations are licensed under the identical terms.

For reprints contact: reprints@medknow.com

How to cite this article: Ekwochi U, Ifediora C, Osuorah CD. A 4-Year prospective study of clinico-bacterial profile and antibiogram of neonatal bacterial sepsis at a tertiary health facility in a resource-limited setting. J Clin Neonatol 2018;7:80-8. 
birth asphyxia $23 \%$. Altogether, they are responsible for $87 \%$ of neonatal deaths. ${ }^{[2,3]}$ In the developing countries, neonatal sepsis (NNS) contributes $30 \%-50 \%$ of neonatal deaths. ${ }^{[4]}$ It accounts for $61 \%$ of neonatal admissions and $29.4 \%$ of neonatal death in the current study center. ${ }^{[5,6]}$ It is described as early-onset sepsis (EOS) when it occurs within the first $72 \mathrm{~h}$ of life and late-onset sepsis (LOS) when it occurs after $72 \mathrm{~h} .{ }^{[7]}$ The causative organisms in EOS are mainly the organisms in the maternal genital tract, labor rooms, or operating theaters, while the nosocomial and the community-acquired organisms are usually responsible for $\mathrm{LOS}^{[8]}$ Risk factors for NNS include, but are not limited to prematurity, low birth weights, prolonged rupture of membrane, asphyxia, and maternal perinatal fever. ${ }^{[9,10]}$ It is important to note that the clinical symptomatology of NNS are subtle and nonspecific, ${ }^{[10]}$ and its definitive diagnosis using positive blood culture, which is the gold standard, could be quite challenging. This is so because in the study setting, a minimum wait period of 48 -h is usually required for result of blood culture to be released to clinicians. ${ }^{[1]}$ Secondly, the cost of blood culture test in our setting is usually borne by patients and their care-givers which is mostly unaffordable for majority of them. ${ }^{[6]}$ Early commencement of antibiotics in NNS enhances good prognosis; ${ }^{[10]}$ it is therefore recommended that every locale should document the organisms predominantly implicated in their newborn infections and their antibiotic sensitivity pattern. Using this pattern, an early empirical antibiotic therapy could be started in cases of sepsis awaiting the blood culture and antibiotic sensitivity to substitute as necessary. ${ }^{[12]}$ In our setting, there is no study documenting the clinical symptomatology, bacterial profile, and antibiotic sensitivity for newborn sepsis, upon which effective empirical therapy could be formulated. The latter strongly underscores the need for this study.

\section{MeTHODS}

\section{Study area}

The study was done at the Special Care Baby Unit (SCBU) of Enugu State University Teaching Hospital (ESUTH), Park Lane, Enugu, Southeast Nigeria. This is a state-owned tertiary health facility that serves as a referral center for specialized medical services for Enugu and the neighboring states. The SCBU cares for sick newborns delivered within the hospital (inborn) or referred from other health facilities (outborn) who presented within the first 28 days of life. It has separate sections for inborn and outborn babies. Each section has a separate complement of medical facilities for the care of the sick babies. The unit is being manned by consultant neonatologists, pediatrics, residents, and nurses, some of which have undergone training in pediatric nursing.

\section{Case definition and recruitment}

This was a case-control and prospective study carried out over a 4-year period from January 2013 to December 2016. Newborns suspected of having septicemia based on clinical symptoms such as fever, refusal to suckle, weakness, vomiting, and abdominal distension are admitted to the sick baby unit of the ESUTH.

After admission, a thorough history is taken documenting the onset of illness, presence of maternal risk factors for NNS such as maternal illnesses, prolonged rupture of membrane ( $>24$ hours to delivery of baby), lower abdominal pain, vaginal discharge, instrumental delivery, place of birth, gestational age at birth, and absence of spontaneous and sustained respiration at birth.

A thorough physical examination is carried out noting signs such as irritability, state of the anterior fontanel, lethargy, jaundice, pallor, organomegaly, depressed primitive flexes, erythema, induration, and umbilical and other orificial discharge. Concurrently, relevant laboratory specimens for sepsis screen are collected. These include complete blood count, swabs where indicated, urinalysis, Gram stain, and blood culture. Further investigations are also carried out as indicated. Because it takes 3-7 days for culture result to be available, a presumptive diagnosis of NNS is made in the presence of suggestive clinical features and/or physical findings, with a supportive preliminary laboratory results. However, the presence of positive bacterial isolate in the blood culture is regarded as confirmatory.

Once a presumptive diagnosis of sepsis is made, and samples taken for relevant laboratory investigations including blood culture, the baby is commenced on empirical broad-spectrum antibiotics. This may be changed depending on sensitivity result upon the retrieval of the blood culture antibiogram, particularly when there are no clinical improvements with the initial antibiotic treatment.

For the purpose of this study, only sick newborns with positive blood culture result were recruited as cases [Figure 1]. For each case, unmatched controls were enrolled under the following measures; gender, birth weight, gestational age at birth, mode of delivery, and place of birth. Each case under the aforementioned measures was matched with its controls in the ratio of at least 1:3. For the purpose of this research, the findings of the general and systemic physical examination for the cases were documented in the Microsoft Excel sheet of the study. The bacteria isolated in the blood culture and their drug sensitivity patterns were also documented. 


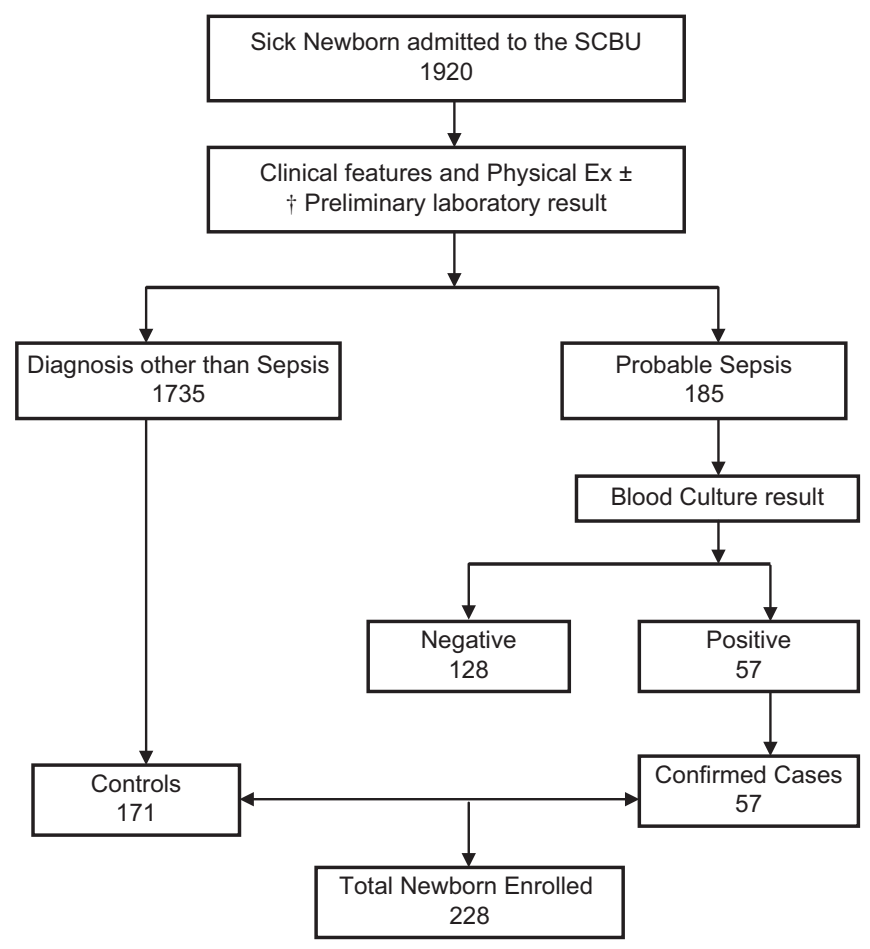

Figure 1: Overview of case definition and recruitment processes of surveyed newborns $\uparrow$ Complete blood Count, Urinalysis or Gram stain

\section{Data analysis}

Analysis was performed using the IBM $^{\circledR}$ SPSS version 24.0 (SPSS Inc., Chicago, IL, USA). Both descriptive (presented as absolute data or as percentages) and inferential analyses were adopted (using both the Pearson Chi-square statistics and logistic regression as indicated). Binary logistic regression (BLR) was preferred regression method (variables were dichotomized where necessary), and two different analyses were carried out.

The first BLR attempted to identify associations with "cases of sepsis," which was the outcome (dependent) variable, while there were six predictor (independent) variables. These predictor variables include birth weight in $\mathrm{kg}(\geq 2.5$ vs. $<2.5)$, place of birth (inborn or outborn), gestational age in completed weeks $(\geq 37$ vs. $<37)$, gender (male and female), mode of delivery (cesarean vs. vaginal), and final outcome (dead vs. alive).

The second set of BLR analysis was done to identify potential associations between various patient characteristics and some clinical features found the cases and included eight outcome (dependent) variables and six predictor (independent) variables. The eight outcome variables, dichotomized as necessary, were birth weight in $\mathrm{kg}(\geq 2.5$ vs. $<2.5)$, place of birth (inborn or outborn), prolonged rupture of membrane, PROM (yes or no), mode of delivery (cesarean required or not required), gestational age in completed weeks
( $\geq 37$ vs. $<37$ ), gender (male and female), age at onset of sepsis ( $\leq 72$ vs. $>72$ ), and finally, age at presentation to the SCBU, $(\leq 72$ vs. $>72)$. On the other hand, the six predictor variables include the presence or absence of clinical features, including asphyxia, hypertonia, jaundice, hepatomegaly, abdominal distention, and primitive reflexes.

It should be noted that, in all cases of the BLR, variables with numbers $<5$ were excluded, and only $P<0.05$ was considered statistically significant.

\section{Ethical consideration}

The study was approved by the Ethical Committee of ESUTH. Written informed consent was obtained from the parents and or caregivers of the subject before recruitment. They were assured that participation is voluntary and withdrawal at any stage of the research is guaranteed. Moreover, all clinical and laboratory findings on their babies will be confidential and can only be utilized in the management of their babies. They were further assured that refusal to participate in the study will not cause any bias in the care of their babies.

\section{ReSULTS}

In all, 1920 newborns were admitted to the SCBU of ESUTH during the study period. Fifty-seven were managed for culture-proven sepsis, resulting to an in-hospital incidence rate of 29.7 per 1000 admitted newborns (95\% confidence interval [CI] 21.9-37.4). Table 1 summarizes the characteristics of all these participants and shows that 140 or $61.4 \%$ of them were males, while the mean birth weight was $2.70 \pm 1.02 \mathrm{~kg}$. Most $(44.3 \%)$ were born at term, but $39 \%$ and $5.3 \%$ were born pre- and post-term, respectively. Majority of the newborns were either born inside within ESUTH $(58.4 \%)$, delivered by spontaneous vaginal delivery (SVD) (59.7\%), and survived (78.9\%). Tables 2-4 show the characteristics of the cases only.

As shown in Table 2, majority (70.2\%) of those who developed sepsis were males, most $(56.6 \%)$ had normal weights ranging from 2.5 to $4.2 \mathrm{~kg}$, and unlike in the overall group, majority $(71.9 \%)$ were born outside ESUTH. Furthermore, $59.6 \%$ were born at term, one-third developed asphyxia, and while $84.2 \%$ of the cases developed within $72 \mathrm{~h}$ of birth, only $18.0 \%$ were admitted to ESUTH after $72 \mathrm{~h}$ of birth.

The clinical features of the newborns with sepsis are summarized in Table 3 and revealed that fever was the most common symptom, with $84.2 \%$ of the presentations manifesting as such. Poor suckling (39.3\%), fast breathing (43.6\%), jaundice (39.3\%), lethargy (31.6\%), and poor cry $(30.4 \%)$ were other fairly common 


\begin{tabular}{|c|c|c|}
\hline Characteristic & Variable & $n(\%)$ \\
\hline \multirow[t]{2}{*}{ Gender $(n=228)$} & Male & $140(61.4)$ \\
\hline & Female & $88(38.6)$ \\
\hline Birth weight $(\mathrm{kg})(n=216)$ & Large $(>4.2)$ & $13(6.0)$ \\
\hline Mean $=2.70$ & Normal (2.5-4.2) & $112(51.9)$ \\
\hline \multirow{2}{*}{$\begin{array}{l}\text { Range }=4.9(0.6 \text { to } 5.5) \\
\mathrm{SD}=1.019\end{array}$} & Low $(1.5-2.4)$ & $63(29.2)$ \\
\hline & Very LBW $(\leq 1.5)$ & $28(13.0)$ \\
\hline \multicolumn{3}{|l|}{ Median $=2.75$} \\
\hline \multirow{3}{*}{$\begin{array}{l}\text { Gestational age (weeks) } \\
(n=228)\end{array}$} & Postdate $(\geq 41)$ & $12(5.30)$ \\
\hline & Term $(37-40)$ & $127(44.3)$ \\
\hline & Preterm $(\leq 36)$ & $89(39.0)$ \\
\hline \multirow{2}{*}{$\begin{array}{l}\text { Place of birth (i.e., whether } \\
\text { inside the tertiary hospital } \\
\text { or outside of it) }(n=226)\end{array}$} & Inborn & $94(41.6)$ \\
\hline & Outborn & $132(58.4)$ \\
\hline \multirow[t]{2}{*}{ Mode of delivery $(n=221)$} & $\begin{array}{l}\text { Spontaneous vagina } \\
\text { delivery }\end{array}$ & $132(59.7)$ \\
\hline & Cesarean section & $89(40.3)$ \\
\hline \multirow[t]{2}{*}{ Outcome $(n=218)$} & Alive & $172(78.9)$ \\
\hline & Dead & $46(21.1)$ \\
\hline
\end{tabular}

LBW - Low birth weight; SD - Standard deviation

symptoms, while vomiting (17.5\%), diarrhea (1.8\%), abdominal distention (15.8\%), excessive cry $(12.5 \%)$, and bleeding from the cord $(3.5 \%)$ were not very common.

As shown in Table 4, depressed primitive reflexes were the only other common physical finding, present in just over half $(50.9 \%)$ of the cases, but hepatomegaly $(21.1 \%)$, splenomegaly $(1.8 \%)$, pallor $(12.5 \%)$, and hypertonia (26.3\%) were not common. Table 4 also shows that about 9-in-10 (92.6\%) of the septic cases survived.

Table 5 reveals the findings of the comparisons between key characteristics of the Cases and those of the Controls using the Chi-squared analysis. It was found that the place of birth $(P=0.02)$ and the final outcome $(P=0.004)$ were significantly associated with the development of sepsis, while gender $(P=0.12)$, birth weight $(P=0.33)$, gestational age $(P=0.53)$, and mode of delivery $(P=0.74)$ were not. Using the BLR, these associations were re-tested, and both associations identified earlier retained their respective significances [Table 6]. As shown, newborns who developed sepsis were $59 \%$ less likely to be born within ESUTH, i.e. to be "inborn" (odds ratio [OR] 0.41; CI $0.20-0.88 ; P=0.02$ ), and were also three-and-half times likely not to survive (OR 3.46; CI 1.11-10.78; $P=0.03$ ). Again, no associations were found between the development of sepsis and birth weight, gestational age, gender, and mode of delivery.

\begin{tabular}{|c|c|c|}
\hline \multicolumn{3}{|c|}{$\begin{array}{c}\text { Table 2: Demographic, pregnancy, and birth } \\
\text { characteristics newborns presenting with sepsis at } \\
\text { the Special Care Baby Unit, Enugu State University } \\
\text { Teaching Hospital, Enugu, Southeast Nigeria }\end{array}$} \\
\hline Characteristic & Variable & $n(\%)$ \\
\hline \multirow[t]{2}{*}{ Gender $(n=57)$} & Male & $40(70.2)$ \\
\hline & Female & $17(29.8)$ \\
\hline \multirow[t]{4}{*}{ Birth weight (kg) $(n=53)$} & Large $(>4.2)$ & $3(5.7)$ \\
\hline & Normal (2.5-4.2) & $30(56.6)$ \\
\hline & Low $(1.5-2.4)$ & $17(32.1)$ \\
\hline & Very LBW $(\leq 1.5)$ & $3(5.7)$ \\
\hline \multirow{3}{*}{$\begin{array}{l}\text { Gestational } \\
\text { age (weeks) }(n=57)\end{array}$} & Postdate $(\geq 41)$ & $4(7.0)$ \\
\hline & Term $(37-40)$ & $34(59.6)$ \\
\hline & Preterm $(\leq 36)$ & $19(33.3)$ \\
\hline \multirow{2}{*}{$\begin{array}{l}\text { Place of birth (i.e., whether } \\
\text { inside the tertiary hospital } \\
\text { or outside of it) }(n=57)\end{array}$} & Inborn & $16(28.1)$ \\
\hline & Outborn & $41(71.9)$ \\
\hline \multirow[t]{2}{*}{ Mode of delivery $(n=57)$} & $\begin{array}{l}\text { Spontaneous vagina } \\
\text { delivery }\end{array}$ & $33(57.9)$ \\
\hline & Cesarean section & $24(42.1)$ \\
\hline \multirow[t]{2}{*}{ PROM ( $n=57)$} & Yes & $16(28.1)$ \\
\hline & No & $41(71.9)$ \\
\hline \multirow[t]{2}{*}{ Asphyxia $(n=57)$} & Yes & $19(33.3)$ \\
\hline & No & $38(66.7)$ \\
\hline Age at presentation to & $\leq 72$ & $41(82.0)$ \\
\hline baby unit (h) $(n=50)$ & $>72$ & $9(18.0)$ \\
\hline
\end{tabular}

Mean $=61.1$

$\mathrm{SE}$ of mean $=14.7$

Range $=0$ to 528

Median $=24$

Age at onset of sepsis (h) $\quad \leq 72 \mathrm{~h} \quad 49$ (84.2)

$(n=57)$

$>72 \mathrm{~h}$

$9(15.8)$

Mean $=64.2$

$\mathrm{SE}$ of mean $=15.1$

Range $=0-528$

Median $=24.0$

PROM - Premature rupture of membrane; SE - Standard error; LBW - Low birth weight

The associations between various patient characteristics and some clinical features found among newborns presenting with sepsis are summarized in Table 7. It was observed that, among newborns with sepsis, whose birth weights were $\geq 2.5 \mathrm{~kg}$ were eight-and-half times more likely to develop asphyxia $(\mathrm{OR}=8.47$; $\mathrm{CI}=1.69-42.48 ; P=0.05)$ and five times more likely to develop hypertonia $(\mathrm{OR}=5.14 ; \mathrm{CI}=1.01-26.10$; $P=0.05)$ than those whose birth weights were $<2.5 \mathrm{~kg}$. In addition, those of them who were born at term or more ( $\geq 37$ weeks) were $74 \%$ less likely to develop hepatomegaly $(\mathrm{OR}=0.26 ; \mathrm{CI}=0.07-0.98 ; P=0.05)$ relative to those born preterm ( $<37$ weeks).

It was also found that septic newborns who developed sepsis at $\leq 72 \mathrm{~h}$ of birth were $86 \%$ less likely to develop 


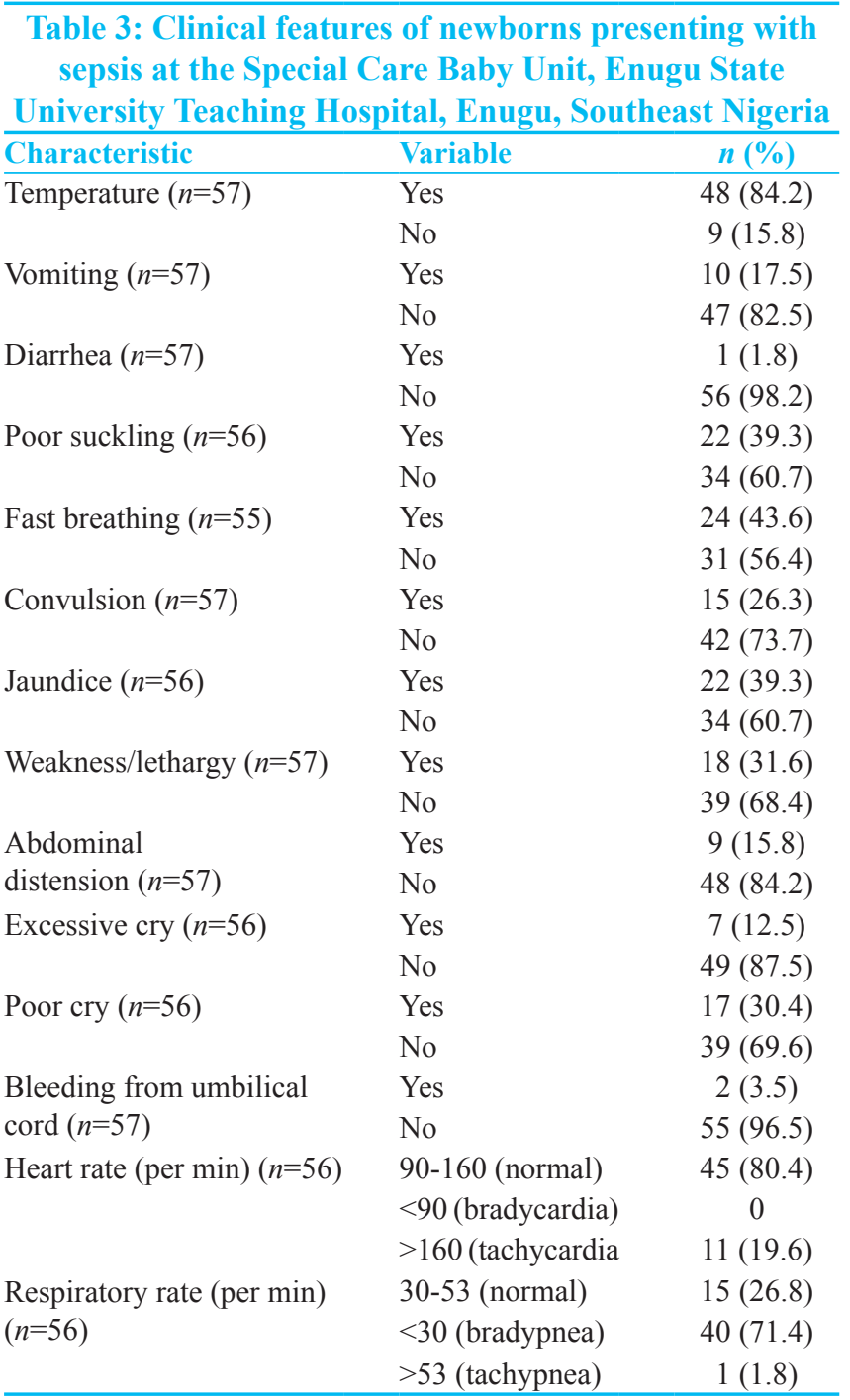

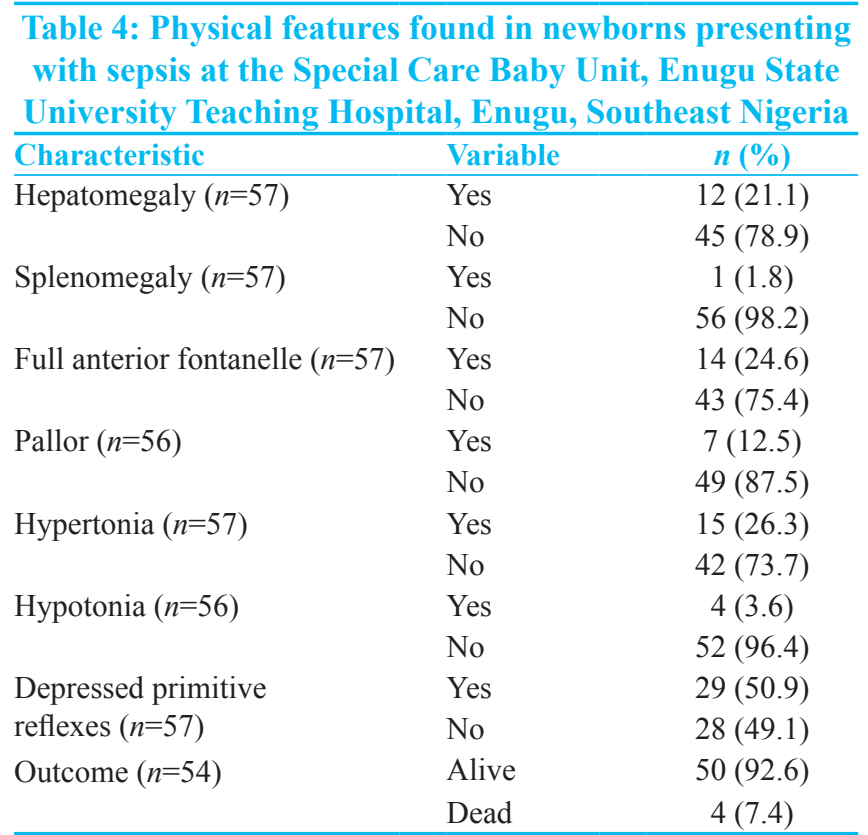

abdominal distention $(\mathrm{OR}=0.14 ; \mathrm{CI}=0.03-0.72$; $P=0.02$ ), while those admitted to the SCBU at $\leq 72$ of birth were $85 \%$ less likely to develop abdominal distension $(\mathrm{OR}=0.15 ; \mathrm{CI}=0.03-0.73 ; P=0.02)$.

Finally, those born in ESUTH were about five times more likely to develop jaundice compared with those born outside $(\mathrm{OR}=4.83 ; \mathrm{CI}=1.36-17.16 ; P=0.02)$.

Table 8 shows the causative organisms implicated in the cases of sepsis, as well as their patterns of antibiotic sensitivities. It reveals that approximately $3-i n-5$ of the cases $(59.6 \%)$ involved coliforms, while one-quarter were from Staphylococcus aureus. The most sensitive antibiotic in the study center is ciprofloxacin with a sensitivity of $49.1 \%$ for coliforms, $15.8 \%$ for $S$. aureus, and $7.0 \%$ for Streptococcus spp. Other fluoroquinolones had similarly high sensitivity. Next to fluoroquinolones are the ceftriaxone and gentamicin while drugs such as amoxicillin, ampicillin, cefixime, and clindamycin were not effective against the common pathogens in the study center [Table 8].

\section{DisCUSSION}

The incidence of culture-proven sepsis in our center was 29.7/1000 newborn admitted to the SCBU of the ESUTH. Another similar study reported an incidence rate of 5.5/1000 birth in a community-based study in developing communities around the world. ${ }^{[13]}$ The far higher incidence rate reported in our study may be related to the fact that it was hospital based as opposed to the community-based method in the referenced study. The high incidence rate of NNS reported in this study could explain the continued high under-5 children mortality rate seen in Sub-Saharan Africa. ${ }^{[14]}$ The World Health Organization in 2004 reported that neonatal death accounted for over a third of deaths in under-5 children in Africa. Among the neonatal deaths reported, NNS and prematurity accounted for more than $80 \%$ of all neonatal mortality. ${ }^{[14]}$ The male to female ratio of 6:1 showing a male preponderance in this study is in line with other reports that have documented male predominance in neonatal infections. ${ }^{[15,16]}$ Higher susceptibility of males to infection from earlier studies is said to be genetically mediated. ${ }^{[17,18]}$

More babies who had sepsis were delivered through SVD compared to cesarean section though this did not attain statistical significance possibly due to small sample size. A similar finding was documented by Veerendra et $a l .{ }^{[19]}$ in a hospital-based study where they found that newborns who had normal vaginal deliveries are 2.29 times more at risk of developing NNS compared to those delivered via cesarean section. The latter is an aseptic surgical procedure and entails strict observance of asepsis compared to the former which is a natural 
Table 5: Comparison of the characteristics of newborns with sepsis (cases) and those without sepsis (controls) for all those admitted at the Special Care Baby Unit, Enugu State University Teaching Hospital, Enugu, Southeast Nigeria, from January 2013 to December 2016

\begin{tabular}{|c|c|c|c|c|c|}
\hline Characteristic & Variable & Number of cases $(\%)$ & Number of controls $(\%)$ & $\chi^{2}$ statistic & $P$ \\
\hline \multirow[t]{2}{*}{ Gender } & Male & $40(70.2)$ & $17(9.9)$ & 2.47 & 0.12 \\
\hline & Female & $17(29.8)$ & $100(90.1)$ & & \\
\hline \multirow[t]{4}{*}{ Birth weight (kg) } & Large $(>4.2)$ & $3(5.7)$ & $10(6.1)$ & 3.41 & 0.33 \\
\hline & Normal (2.5-4.2) & $30(56.6)$ & $82(50.3)$ & & \\
\hline & Low $(1.5-2.4)$ & $17(32.1)$ & $46(28.2)$ & & \\
\hline & Very LBW $(\leq 1.5)$ & $3(5.7)$ & $25(15.4)$ & & \\
\hline \multirow[t]{3}{*}{ Gestational age (weeks) } & Postdate $(\geq 41)$ & $4(7.0)$ & $8(4.7)$ & 1.29 & 0.53 \\
\hline & Term $(37-40)$ & $34(59.6)$ & $70(52.6)$ & & \\
\hline & Preterm $(\leq 36)$ & $19(33.3)$ & $93(42.7)$ & & \\
\hline \multirow[t]{2}{*}{ Place of birth } & Inborn & $16(28.1)$ & $78(46.2)$ & 5.74 & $0.02 *$ \\
\hline & Outborn & $41(71.9)$ & $91(53.8)$ & & \\
\hline \multirow[t]{2}{*}{ Mode of delivery } & $\begin{array}{l}\text { Spontaneous vagina } \\
\text { delivery }\end{array}$ & $33(57.9)$ & $99(60.4)$ & 0.11 & 0.74 \\
\hline & Cesarean section & $24(42.1)$ & $65(39.6)$ & & \\
\hline \multirow[t]{2}{*}{ Outcome } & Alive & $50(96.6)$ & $122(74.4)$ & 8.06 & $0.004 *$ \\
\hline & Dead & $4(7.4)$ & $42(25.6)$ & & \\
\hline
\end{tabular}

*Statistically significance is set at $P \leq 0.05$. LBW - Low birth weight

\begin{tabular}{|c|c|c|c|c|}
\hline \multicolumn{5}{|c|}{$\begin{array}{c}\text { Table 6: Binary logistic regression showing associations } \\
\text { between the development of sepsis and some } \\
\text { characteristics of newborns at the Special Care Baby } \\
\text { Unit, Enugu State University Teaching Hospital, Enugu, } \\
\text { Southeast Nigeria }\end{array}$} \\
\hline \multirow{2}{*}{$\begin{array}{l}\text { Outcome (dependent) } \\
\text { variables }\end{array}$} & \multirow[t]{2}{*}{ OR } & \multicolumn{2}{|c|}{$95 \%$ CI of OR } & \multirow[t]{2}{*}{ Significance $(P)$} \\
\hline & & Lower & Upper & \\
\hline $\begin{array}{l}\text { Birth weight }(\mathrm{kg}) \\
(\geq 2.5 \text { vs. }<2.5)\end{array}$ & 1.09 & 0.39 & 3.07 & 0.87 \\
\hline $\begin{array}{l}\text { Gestational age (weeks) } \\
(\geq 37 \text { vs. }<37)\end{array}$ & 0.91 & 0.31 & 2.65 & 0.86 \\
\hline Gender (male vs. female) & 0.74 & 0.37 & 1.50 & 0.40 \\
\hline $\begin{array}{l}\text { Final outcome (dead } \\
\text { vs. alive) }\end{array}$ & 3.46 & 1.11 & 10.78 & $0.03 *$ \\
\hline $\begin{array}{l}\text { Mode of delivery } \\
\text { (caesarean vs. vaginal) }\end{array}$ & 1.23 & 0.60 & 2.51 & 0.57 \\
\hline $\begin{array}{l}\text { Place of birth (inborn } \\
\text { vs. outborn) }\end{array}$ & 0.41 & 0.20 & 0.88 & $0.02 *$ \\
\hline
\end{tabular}

*Statistically significance is set at $P \leq 0.05$. OR - Odds ratio; CI - Confidence interval

process, and newborns delivered through it are exposed to organisms which naturally inhabits the mother's birth canals. Such organisms have long been implicated as causes of early-onset NNS. ${ }^{[17]}$

In our study, it was observed that most newborns with sepsis were delivered outside the study center. This finding corroborates a study in Nepal which documented a higher prevalence of sepsis among outborns compared to inborn babies. ${ }^{[20]}$ The explanation given in the referenced study which is also true in our environment was that some of these deliveries done outside could occur at home or maternity homes where basic aseptic procedures during childbirth may not be followed. In addition, these babies delivered outside and referred to our facility are more likely to have been exposed to microorganism in the environment during transportation further increasing the likelihood of infectivity.

The proportion of newborns who died from NNS in the current study is lower (7.4\%) compared to $19 \%$ documented by a similar hospital-based study on bacteriologically proven cases of NNS at the University of Calabar Teaching Hospital in Southern Nigeria. ${ }^{[21]}$ These figures are still unacceptably high in both scenarios compared to figures in developed climes. These high case-fatality rates reported in both studies are particularly troubling because these newborns had blood culture and antibiogram which should enhance the use of the most sensitive antibiotics in their treatment. However, factors such as late presentation noted in our study, ${ }^{[22]}$ particularly among newborns delivered outside, may have contributed to the high mortality rate seen in this study.

None of the clinical features encountered in newborns with sepsis in our study was significantly correlated with the diagnosis of sepsis. However, fever and depressed primitive reflexes were the most frequently encountered clinical presentation in septic neonates. This re-affirms the long documented nonspecific and subtle signs and symptoms of $\mathrm{NNS}^{[10]}$ and underscores the importance of careful evaluation of neonates with suspected sepsis and the need for a culture in the definite diagnosis of NNS. 
Table 7: Binary logistic regression showing associations between various patient characteristics and some clinical features found in among newborns presenting with sepsis at the Special Care Baby Unit, Enugu State University Teaching Hospital, Enugu, Southeast Nigeria

\begin{tabular}{|c|c|c|c|c|c|}
\hline \multirow[t]{2}{*}{ Outcome (dependent) variables } & \multirow[t]{2}{*}{ Predictor (independent) variables } & \multirow[t]{2}{*}{ OR } & \multicolumn{2}{|c|}{$95 \%$ CI of OR } & \multirow[t]{2}{*}{ Significance $(P)$} \\
\hline & & & Lower & Upper & \\
\hline \multirow[t]{3}{*}{ Birth weight $(\mathrm{kg})(\geq 2.5$ vs. $<2.5)$} & Asphyxia (yes vs. s no) $(n=53)$ & 8.47 & 1.69 & 42.48 & $0.01 *$ \\
\hline & Hypertonia (present vs. absent) $(n=53)$ & 5.14 & 1.01 & 26.10 & $0.05^{*}$ \\
\hline & Jaundice (present vs. absent) $(n=52)$ & 3.16 & 0.98 & 10.24 & 0.06 \\
\hline \multirow[t]{3}{*}{ Gestational age (weeks) ( $\geq 37$ vs. $<37$ ) } & Asphyxia (yes vs. no) $(n=57)$ & 3.88 & 0.97 & 15.59 & 0.06 \\
\hline & Hepatomegaly (present vs. absent) $(n=57)$ & 0.26 & 0.07 & 0.98 & $0.05^{*}$ \\
\hline & Hypertonia (present vs. absent) $(n=57)$ & 4.42 & 0.88 & 22.14 & 0.07 \\
\hline Age at onset of sepsis ( $\leq 72$ vs. $>72)$ & Abdominal distention (yes vs. no) $(n=50)$ & 0.14 & 0.03 & 0.72 & $0.02 *$ \\
\hline \multirow{2}{*}{$\begin{array}{l}\text { Age at presentation to hospital (h) } \\
(\leq 72 \text { vs. }>72)\end{array}$} & Abdominal distention (yes vs. no) $(n=57)$ & 0.15 & 0.03 & 0.73 & $0.02 *$ \\
\hline & Diminished primitive reflexes (yes vs. no) $(n=57)$ & 4.50 & 0.85 & 23.95 & 0.08 \\
\hline Place of birth (inborn vs. outborn) & Jaundice (present vs. absent) $(n=56)$ & 0.46 & 0.24 & 0.87 & $0.02 *$ \\
\hline
\end{tabular}

**Statistically significance is set at $P \leq 0.05$; Only results with $P<0.10$ are included

Coliform bacteria were the most common isolated organisms in the study center followed by $S$. aureus. Escherichia coli was the most common coliform seen. Our diagnostic laboratory lacks the facilities to specifically isolate other forms of coliforms; hence, they were all reported as coliforms. Similar bacteriological profile was reported in another, hospital-based study, which isolated E. coli as the most common causative organism followed by Staphylococcus. ${ }^{[23]}$ The former is a common flora in the genitourinary tract and is vertically transmitted to newborn in utero or at time of birth, while the latter is commonly transmitted by hospital workers and relatives. ${ }^{[4]}$ Contrary to our finding, another hospital-based study in a Neonatal Intensive Care Unit reported a higher incidence of $S$. aureus than coliform bacteria such as Klebsiella. ${ }^{[25]}$ The variation in the isolated organism among centers strongly supports the need for health facilities caring for these vulnerable newborns to document the predominant cause of sepsis that could guide the initiation of antibiotics empirically in suspected cases.

Finally, our study showed that drugs such as ceftriaxone and gentamicin recorded intermediate sensitivity, while ampicillin, amoxicillin, and clindamycin had almost zero sensitivity to cultured bacteria. It is not surprising to note the rising tide of resistance to previously sensitive, available, and affordable penicillin-like the amoxicillin. In the study environment, it is common practice for antibiotics to be dispensed and purchased over the counter without prescription. The authors have previously documented very high prevalence of use and misuse of antibiotics by caregivers in the treatment of common childhood illness in the same environment. ${ }^{[26,27]}$ Such practice could greatly enhance the emergence and spread of resistant strains of microbes.

It is worrisome to note from our study that quinolones, such as ciprofloxacin, ofloxacin, and pefloxacin, were the most sensitive antibiotics to the predominant isolates seen in our study. Although there are concerns for possible adverse effects such as arthropathy and tendinitis associated use of quinolones, several large retrospective studies in children have not associated use of fluoroquinolones with long-term joint abnormality or growth impairment. ${ }^{[28-30]}$ However, more data from controlled trials are needed to further elucidate the safety profile of these drugs in children. The general recommendation has been that its use should be guided by clear medical rationale and careful monitoring. Hence, authors recommend them only when benefits outweigh the potential risk, especially to organism that has demonstrated multidrug resistance.

\section{Concluesion}

Our study reported a high incidence and mortality rate of NNS in Enugu. None of the clinical features reported in septic neonates were strongly correlated with a diagnosis of septicemia in surveyed newborns. Coliforms and $S$. aureus accounted for majority of bacterial isolated in the culture samples of these septic neonates. A high incidence of bacterial resistance to commonly available antibiotics such as penicillins and cephalosporins was also noted in our environment. Quinolones with an inconclusive safety profile in children remain the most sensitive antibiotics for NNS in our environment.

\section{Financial support and sponsorship}

Nil.

\section{Conflicts of interest}

There are no conflicts of interest.

\section{REFERENCES}

1. Chiesa C, Panero A, Osborn JF, Simonetti AF, Pacifico L. Diagnosis of neonatal sepsis: A clinical and laboratory challenge. Clin Chem 2004;50:279-87. 


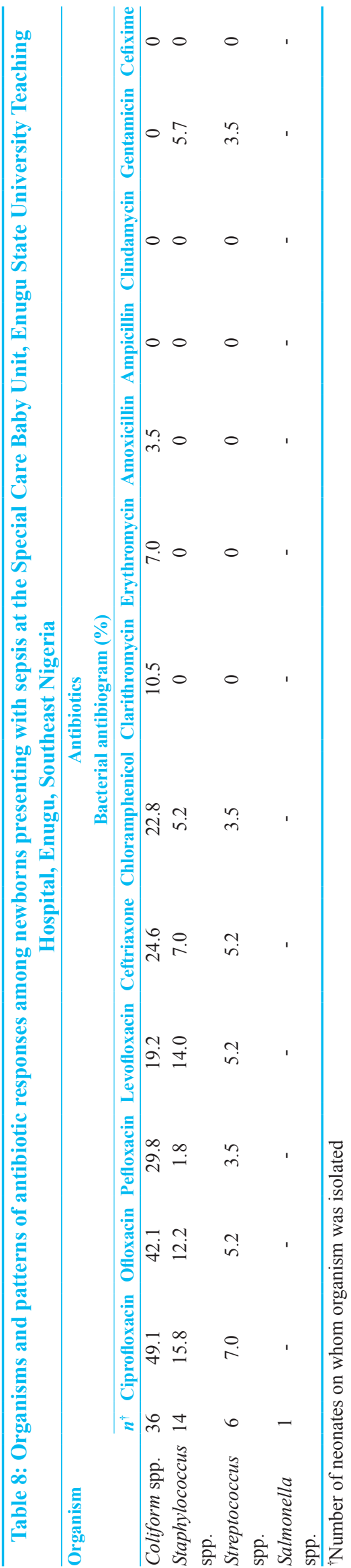

2. WHO. World Health Report 2005: Make Every Mother and Child Count. Geneva: WHO; 2005.

3. Lawn JE, Cousens S, Zupan J. 4 million neonatal deaths: When? Where? Why? Lancet 2005;365:891-900.

4. Antia-Obong CE, Utsalo SJ, Udo JJ. Neonatal septicemia in calabar, Nigeria. Cent Afr J Med 1992;36:161-5.

5. Ekwochi U, Ndu IK, Nwokoye IC, Ezenwosu OU, Amadi OF, Osuorah $\mathrm{D}$, et al. Pattern of morbidity and mortality of newborns admitted into the sick and special care baby unit of Enugu State University Teaching Hospital, Enugu state. Niger J Clin Pract 2014; 17:346-51

6. Ekwochi U, Osuorah DC, Ndu IK, Ezenwosu OU, Amadi OF, Nwokoye IC, et al. Out-of-pocket cost of managing sick newborns in Enugu, Southeast Nigeria. Clinicoecon Outcomes Res 2014;6:29-35.

7. Al-Zwaini EJ. Neonatal septicaemia in the neonatal care unit, Al-Anbar Governorate, Iraq. East Mediterr Health J 2002;8:509-14.

8. Sankar MJ, Agarwal R, Deorari AK, Paul VK. Sepsis in the newborn. Indian J Pediatr 2008;75:261-6.

9. Ben Hamida Nouaili E, Harouni M, Chaouachi S, Sfar R, Marrakchi Z. Early-onset neonatal bacterial infections: A retrospective series of 144 cases. Tunis Med 2008;86:136-9.

10. Ahmed Z, Ghafoor T, Waqar T, Ali S, Aziz S, Mahmud S, et al. Diagnostic value of $\mathrm{C}$ - reactive protein and haematological parameters in neonatal sepsis. J Coll Physicians Surg Pak 2005;15:152-6.

11. Buttery JP. Blood cultures in newborns and children: Optimising an everyday test. Arch Dis Child Fetal Neonatal Ed 2002;87:F25-8.

12. Asuquo UA. Antibiotic therapy in neonatal septicemia (Editorial). Niger J Paediatr 1996;23:1-3.

13. Thaver D, Zaidi AK. Burden of neonatal infections in developing countries: A review of evidence from community-based studies. Pediatr Infect Dis J 2009;28:S3-9.

14. World Health Organization. The Global Burden of Disease: 2004 Update. Available from: http://www.who.int/healthinfo/ global_burden_disease/GBD_report_2004update_part2.pdf. [Last accessed on 2017 May 21].

15. Bhat RY, Lewis LE, Vandana KE. Bacterial isolates of early-onset neonatal sepsis and their antibiotic susceptibility pattern between 1998 and 2004: An audit from a center in India. Ital J Pediatr 2011;37:32.

16. Stoll BJ, Gordon $\mathrm{T}$, Korones $\mathrm{SB}$, Shankaran $\mathrm{S}$ et al. Earlyonset sepsis in very low birth weight neonates: a report from the National Institute of Child Health and Human Development Neonatal Research Network. J Pediatr. 1996 Jul;129:72-80.

17. Klinger G, Levy I, Sirota L, Boyko V, Reichman B, Lerner-Geva L, et al. Epidemiology and risk factors for early onset sepsis among very-low-birthweight infants. Am J Obstet Gynecol 2009;201:38.e1-6.

18. Bauman KA, Han MK. Gender difference in susceptibility outcomes and pathophysiology of sepsis. In: Principles of Gender-Specific Medicine $2^{\text {nd }}$ ed., Ch 27 p291-303. Elsevier Inc. 2010.

19. Veerendra M, Saksham A, Ruby S, Abhishek A, Nikhar A, Aditi M. Relationship between gestational age and mode of delivery with neonatal sepsis. Int $\mathrm{J}$ Contemp Pediatr 2016;3:891-2.

20. Khinchi YR, Kumar A, Yadav S. Profile of neonatal sepsis. J Coll Med Sci Nepal 2010;6:1-6.

21. Anah MU, Udoh JJ, Ochigbo SO. Neonatal sepsis in Calabar, Nigeria. Trop Doct 2008;38:126-8. 
22. Ekwochi U, Ndu IK, Osuorah CD, Onah KS, Obuoha E, Odetunde OI, et al. Delays in healthcare delivery to sick neonates in Enugu South-East Nigeria: An analysis of causes and effects. J Public Health (Oxf) 2016;38:e171-7.

23. Aurangzeb B, Hameed A. Neonatal sepsis in hospital-born babies: Bacterial isolates and antibiotic susceptibility patterns. J Coll Physicians Surg Pak 2003;13:629-32.

24. Kayange N, Kamugisha E, Mwizamholya DL, Jeremiah S, Mshana SE. Predictors of positive blood culture and deaths among neonates with suspected neonatal sepsis in a tertiary hospital, Mwanza-Tanzania. BMC Pediatr 2010;10:39.

25. Sharma P, Kaur P, Aggarwal A. Staphylococcus aureus - The predominant pathogen in the neonatal ICU of a tertiary care hospital in Amritsar, India. J Clin Diagn Res 2013;7:66-9.

26. Ekwochi U, Chinawa JM, Obi I, Obu HA, Agwu S. Use and/or misuse of antibiotics in management of diarrhea among children in Enugu, Southeast Nigeria. J Trop Pediatr 2013;59:314-6.

27. Ekwochi U, Chinawa JM, Osuorah CD, Odetunde OI, Obu HA, Agwu S, et al. The use of unprescribed antibiotics in management of upper respiratory tract infection in children in Enugu, South East Nigeria. J Trop Pediatr 2014;60:249-52.

28. Yee CL, Duffy C, Gerbino PG, Stryker S, Noel GJ. Tendon or joint disorders in children after treatment with fluoroquinolones or azithromycin. Pediatr Infect Dis J 2002;21:525-9.

29. Chalumeau M, Tonnelier S, D'Athis P, Tréluyer JM, Gendrel D, Bréart $\mathrm{G}$, et al. Fluoroquinolone safety in pediatric patients: A prospective, multicenter, comparative cohort study in France. Pediatrics 2003;111:e714-9.

30. Noel GJ, Bradley JS, Kauffman RE, Duffy CM, Gerbino PG, Arguedas A, et al. Comparative safety profile of levofloxacin in 2523 children with a focus on four specific musculoskeletal disorders. Pediatr Infect Dis J 2007;26:879-91.

\section{Author Help: Reference checking facility}

The manuscript system (www.journalonweb.com) allows the authors to check and verify the accuracy and style of references. The tool checks the references with PubMed as per a predefined style. Authors are encouraged to use this facility, before submitting articles to the journal.

- The style as well as bibliographic elements should be $100 \%$ accurate, to help get the references verified from the system. Even a single spelling error or addition of issue number/month of publication will lead to an error when verifying the reference.

- Example of a correct style Sheahan P, O'leary G, Lee G, Fitzgibbon J. Cystic cervical metastases: Incidence and diagnosis using fine needle aspiration biopsy. Otolaryngol Head Neck Surg 2002;127:294-8.

- Only the references from journals indexed in PubMed will be checked.

- $\quad$ Enter each reference in new line, without a serial number.

- $\quad$ Add up to a maximum of 15 references at a time.

- If the reference is correct for its bibliographic elements and punctuations, it will be shown as CORRECT and a link to the correct article in PubMed will be given.

- If any of the bibliographic elements are missing, incorrect or extra (such as issue number), it will be shown as INCORRECT and link to possible articles in PubMed will be given. 